\title{
Food Cultures
}

Introduction

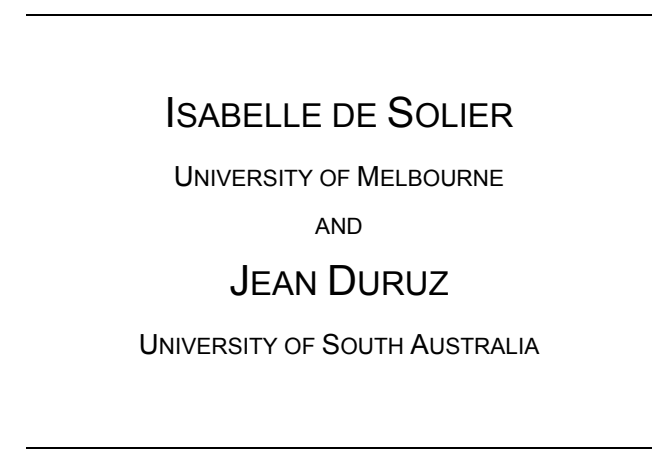

Food is central to everyday life. It is not only on our tables daily, but also on our television screens. It is the domain of the celebrity chef and the home cook, as well as the home cook with celebrity aspirations. Our relationship to food, to its production and consumption, is shaped by place and space, but also by time, memory and nostalgia. It is elaborated through a range of social practices-from farming and gardening, to shopping, cooking and eating out-which are shaped through a series of dichotomies: good and bad, fast and slow, high and low, modern and traditional. The material culture of food, and its associated practices and taste formations, have long played a key role in the creation and maintenance of social identities based on ethnicity, nation, gender and class; yet in global modernity, they are increasingly mobilised in the construction of hybrid, fluid, reflexive identities and lifestyles.

Despite this importance of food to identity and everyday life, the topic has been relatively neglected in cultural studies until recently. Perhaps it was considered too ordinary to warrant attention, as lacking the glamour or the association with youth 
characteristic of earlier concerns in the field. Disciplines such as anthropology and sociology began to address the significance of food in the 1960s and 1970s, but it was not until the early twenty-first century that cultural studies scholars directed close attention to the issue, most notably with the publication of the foundational text Food and Cultural Studies. ${ }^{1}$ Over the past decade, one of the main contributions of cultural studies to the study of food has been its historical and textual analysis of food media, including cookbooks, food television and the rise of celebrity chefs. In this collection we take a different approach, to explore what cultural studies can offer the study of food beyond textual understandings of media-and, in particular, how qualitative empirical research can enhance our contribution to the study of food. The articles collected here demonstrate the many and varied ways in which food matters to individuals, communities and society, and why it should matter to cultural studies.

Isabelle de Solier's article opens the collection by taking up the relationship between food and the self and, in particular, how food is used to craft the reflexive self-identity of the 'foodie'. Drawing on ethnographic research with foodies in Melbourne, Australia, she examines the moralities of consumption which govern the process of making a self through food in late modern consumer culture. Her analysis focuses on two consumption practices which are central to foodie lifestyles-fine dining and shopping-and reveals how different moral registers operate within each practice: while the former is governed by a moral asceticism which aims to restrict consumption and spend less money, the latter is governed by what she calls a 'morality of quality' which involves a willingness to spend more money. This, argues de Solier, is because while both constitute forms of luxury consumption, only fine dining is regarded as such by foodies; in contrast, they consider buying expensive 'quality' food for the home to not only be 'right', but a necessity.

In contrast to the rarefied world of foodies, we now enter the homely spaces of the traditional kitchen-a quintessentially nostalgic setting of everyday baking and beloved family dishes. Two articles focus on the production of specific foods within this context and their relationships to identity-personal, familial, community and beyond. Sian Supski's article reworks the iconic sponge cake in Australia-that familiar confection of eggs, sugar, flour and vanilla-as a resonant 'carrier' of meanings and relationships. Using Lisa Heldke's 'thoughtful practice' together with 
her own contribution of 'anxious practice' as critical theoretical tools, Supski is able to trace myriad resonances from intergenerational relationships among women in her family and from their kitchens-whether the domain of a slow-burning woodstove or a favourite pinewood table, repositioned in a smart, urban setting. Primarily, however, the presence of Aunty Sylvie's sponge in the kitchen allows a meditation on cookbooks and the 'making' of nostalgia. According to Supski, 'gustatory nostalgia' has productive force, not only enabling returns to the past but also sparking negotiations with our presents and futures. To taste the sponge, then, is to sense its meanings, stories and histories.

For Tamara Kohn, it is the foods of the Thanksgiving dinner-stuffed turkey and pumpkin pie-which provide a rich site for the analysis of identity. She focuses on the recipes for these dishes which are used and adapted by first and secondgeneration immigrants in America, as well as Americans living abroad. Kohn argues that the experiences, memories and associations individuals evoke in the deconstruction of holiday recipes shows, on the one hand, how ideas about 'tradition' and a desire to celebrate family and community through the sacred ritual of baking, serving and consuming a 'standard' Thanksgiving holiday meal allow one to feel part of an imagined global American community. On the other hand, it also reveals how choices of ingredients, form and context may celebrate individual and familial distinctiveness that is traced to (sometimes contested) memories of childhood and ethnic background as well as to exploration, innovation and experience in the world at large through travel, migration and imagination.

Continuing this thread of travel and migration, the following three articles tease out meanings of ethnicity embedded in cultures of food production and consumption. Primarily, these articles trace the complex effects of migration and global population flows upon homemaking, everyday food practices and feelings of belonging. Each, however, offers a different 'taste' of this. Jean Duruz's article focuses on a small Ethiopian restaurant established by former refugees in her suburban neighbourhood in Adelaide, Australia-a restaurant that not only serves local communities of Ethiopians but is also well known for its ethic of hospitality to 'others'. Through the motifs of 'hands' and 'spice', the article traces the figure of the matriarch-the significance of her own, embodied culinary learning as well her induction of 'others' into the rules of hand-washing, eating by hand, and eating 
communally. The article plays with a number of contradictions, asking such questions as: Who is the cosmopolitan in this setting? Who is the host and who is the guest? As customers sit at the tables of Addis Ababa Café, Derrida's position on hospitality and forgiveness gives us cause to reflect. Eating as a 'guest' at this table is certainly not without its ambivalent moments. On the other hand, for the 'host', the power to give, as well as to receive, grants a limited visibility to, and acknowledgement of, the migrant subject.

Ben Highmore's article, on the other hand, enters completely different territory. With his project framed as a search for 'a socially oriented aesthetics'-one of 'sensorial engagement' - rather than the building of a set of rules for evaluating, for example, works of art, Highmore offers hints for reworking the project of cultural studies itself and, relatedly, studies of food and food cultures. The beginnings of this argument are microcosmic, two sentences in a novel. The first is a richly evocative description of foods in a Pakistani convenience store in the north of England; the second a prosaic account of a woman taking coriander from a neighbour's garden. From these fragmentary beginnings, Highmore uses 'critical regionalism' and 'gastropoetics' to take the reader on imagined journeys in ever-widening circles through migration history from the subcontinent to Britain, through the effects of this migration on British cities from the late nineteenth century onwards, the placemaking practices of Pakistani traders, the worlds of 'regions'-overlapping imaginaries of religion, language, family and food. At the end of the day, however, the argument comes full circle to the domestic kitchen and garden and their connectedness to these wider worlds-an engagement with 'the mix and multitude of life' that Highmore finds politically satisfying.

The concern with questions of migrant cuisine culminates with Tammi Jonas's article, which takes up the question of vernacular foodways and cosmopolitanism. Employing a mixed methodology of ethnography in Australia, Vietnam and India, auto-ethnography and the textual analysis of Australian migrants' biographies, she uses the stories of 'insiders' and 'outsiders' to explore the importance of the vernacular in foodways-those cultural traditions, rituals and practices centred around food-and the implications of authenticity in the maintenance of homely identities and the development of cosmopolitan ones. Jonas argues that claims of authenticity perform different roles depending on whether one is demanding or 
displaying 'it', whether considered an 'insider' or an 'outsider', whether 'at home' or 'away'.

In the afterword to the collection, Toby Miller reflects on the crucial issue of food sovereignty, and the challenges posed by the articles collected here for future cultural studies of food. He identifies a series of key questions that these articles provoke: questions of political economy, policy, environment, nature, science, health, inequality and hybridity. Miller argues:

the culture of food is not just a series of texts to be read, coefficients of political and economic power to be exposed, or industrial objects to be analysed. Rather, food is all these things: a hybrid monster, coevally subject to rhetoric, status, and technology-to meaning, power and science.

Therein lies the challenge for cultural studies, if we are to comprehensively tackle and understand the material and symbolic importance of food in the twenty-first century.

\section{-ACKNOWLEDGEMENTS}

We would like to thank the reviewers who kindly donated their time to referee the articles in this collection.

${ }^{1}$ Bob Ashley, Joanne Hollows, Steve Jones and Ben Taylor, Food and Cultural Studies, Routledge, London and New York, 2004.
} 